\title{
The dilemma of self-monitoring of blood glucose
}

\author{
M. B. Davidson
}

Published online: 18 January 2007

(C) Springer-Verlag 2007

Keywords Blood glucose $\cdot$ Self monitoring

of blood glucose · Type 2 diabetes

\begin{tabular}{|c|c|}
\hline Abbrevi & tions \\
\hline ROSSO & Retrolective Study 'Self-monitoring of Blood \\
\hline & $\begin{array}{l}\text { Glucose and Outcome in Patients with Type } 2 \\
\text { Diabetes' }\end{array}$ \\
\hline SMBG & self-monitoring of blood glucose \\
\hline
\end{tabular}

In a paper published in Diabetologia last year, Martin et al. [1] reported that self-monitoring of blood glucose (SMBG) in the observational retrospective cohort Retrolective Study 'Self-monitoring of Blood Glucose and Outcome in Patients with Type 2 Diabetes' (ROSSO) was associated with significantly decreased diabetes-related morbidity and all-cause mortality even after adjusting for age, sex, comorbidities at diagnosis of diabetes (hypertension, CHD and history of stroke), fasting plasma glucose concentrations, triacylglycerol levels and treatment. These findings remained true for patients not taking insulin. In contrast, in the present issue of Diabetologia, Davis et al. [2] report that, in the observational, prospective Fremantle study, SMBG was not associated with improved outcomes of diabetes-related morbidity, cardiac death or all-cause mortality after adjustment for confounders. The confound-

\section{B. Davidson $(\square)$}

Clinical Center for Research Excellence,

Charles R. Drew University,

1731 East 120th Street,

Los Angeles, CA 90059, USA

e-mail: mayerdavidson@cdrewu.edu ers adjusted for in the Fremantle study were age, sex, duration of diabetes, prior CHD, prior peripheral arterial disease, neuropathy, retinopathy, microalbuminuria, systolic blood pressure, total serum cholesterol and current smoking. Surprisingly, there was a significant $79 \%$ increased risk of cardiovascular mortality in those patients who were not taking insulin but were performing SMBG.

How can the disparate results of these two large studies be explained and what lessons can we learn from them? First, there are many factors that might impinge on the outcomes, especially the macrovascular ones, and taking all the appropriate confounders into account may be problematic. Second, there may be a self-selection process for physicians in terms of who is recommended for, and patients who perform, SMBG. Evidence for the former is the finding that those who perform SMBG have higher glycaemia than those who do not $[1,3]$. Evidence for the latter was supplied by a large observational retrospective health plan study in which patients who performed SMBG more frequently had lower $\mathrm{HbA}_{1 \mathrm{c}}$ levels [4]. However, a self-administered questionnaire or a computer-assisted telephone interview administered to plan members $(83 \%$ of whom responded) revealed that self-care practices and healthy lifestyle behaviours were significantly more common in patients who performed SMBG more frequently.

By definition, an observational study is not an experimental one, i.e. interventions are chosen rather than randomly assigned. This leads to the possibility of selection bias which, in turn, means that outcomes may not be caused by the intervention under study [5]. Although identifiable differences can be taken into account when the data are analysed, one cannot be certain that these adjustments are adequate because all of the relevant differences may not be 
known [5]. The differences in the confounders considered in the ROSSO [1] and Fremantle [2] studies may have contributed to their contradictory conclusions. Randomised trials circumvent this problem and provide reliable estimates of the effect of the intervention.

Randomised trials studying the effect of SMBG in insulin-requiring patients would not be ethical, as a number of observational trials have shown that $\mathrm{HbA}_{1 \mathrm{c}}$ levels are inversely related to the frequency of SMBG measurements [4, 6-11]. However, SMBG values must be acted on for improved control (a point that I will return to later). In one study, lower $\mathrm{HbA}_{1 \mathrm{c}}$ levels were seen in those insulinrequiring type 2 diabetic patients who self-adjusted their insulin doses, but not in those who did not [12]. With few exceptions, observational studies evaluating the frequency of SMBG and changes in $\mathrm{HbA}_{1 \mathrm{c}}$ levels in patients not taking insulin have shown no effect [13].

Nine allegedly randomised controlled trials evaluating the effect of SMBG on $\mathrm{HbA}_{1 \mathrm{c}}$ levels in type 2 diabetic patients not taking insulin have been identified in two recent reviews $[14,15]$. Five of these showed no effect [2, 16-19]. One of these perhaps deserves special mention because although it was a small study, it was a truly blinded, randomised trial, with clinical decisions being made by a single provider who was unaware of the SMBG status of the patients [19]. The provider was a nurse who followed detailed treatment algorithms. All patients were seen an equal number of times over 6 months by a dietitian. Patients in the SMBG group were instructed to measure before and after different meals, 6 days/week (45\% compliance), and the values were utilised in the nutritional counselling. There was a similar fall in $\mathrm{HbA}_{1 \mathrm{c}}$ levels $(\% \pm$ $\mathrm{SD})$ from baseline between the control group $(-0.6 \pm 1.6)$ and the SMBG group $(-0.8 \pm 2.1)$.

The four 'positive' studies had flaws that raise serious questions about the conclusion that SMBG per se led to significantly lower $\mathrm{HbA}_{1 \mathrm{c}}$ levels. In three of them, the SMBG group received either more intensive counselling [20] or more intensive treatment along with the increased counselling [21, 22] compared with the control group. Furthermore, in one of these three studies, not only were patients taking insulin or oral agents alone combined, but those in the intervention group (who received counselling over the internet) who failed to provide SMBG values for $>3$ weeks were dropped from the study [22]. In the fourth study, there was a huge dropout rate: $40 \%$ in the control group and $48 \%$ in the SMBG group [23]. If the SMBG dropout subgroup was enriched with those patients who were showing the least response, the results could be due to self-selection.

It seems fair to say that, at present, SMBG has not been shown to be beneficial in diabetic patients not taking insulin. However, theoretically, SMBG could (1) educate patients; (2) motivate them; (3) document hyperglycaemia so that action could be taken to reduce it acutely; (4) be used by physicians to adjust oral glucose-lowering drugs; and (5) document hypoglycaemia. Regarding education, few patients receive meaningful feedback from their healthcare providers regarding their SMBG results. In addition, postprandial glucose values (or better yet, the difference between pre- and postprandial values) would serve to educate patients regarding which foods (and how much) cause the greatest postprandial increase. However, few patients are instructed to measure at these times. Most simply measure before breakfast, and some also measure before supper. Thus, the educational potential of SMBG is lost. Regarding motivation, preprandial values are lower than postprandial ones and are therefore not such good motivators.

Insulin-taking patients who have elevated (or decreased) preprandial SMBG values can adjust their shortacting insulin dose, or change the timing or content of the meal to acutely react to the measured value. Patients on pills have fewer options. Changing the content of the meal could be helpful, but unless they are taking a glinide or an $\alpha$-glucosidase inhibitor, medication adjustments will not help. Although there are no data on how often physicians adjust oral doses based on SMBG values instead of laboratory tests, this is probably not very common. Finally, since hypoglycaemia is unusual and sporadic in patients not taking insulin, SMBG for this purpose alone would not seem warranted.

The cost of this unproven modality in diabetic patients not taking insulin is enormous, at least in the USA [13]. Medicare B is an insurance programme provided by the government for patients aged $\geq 65$ years who agree to pay the premiums. The cost for SMBG (strips, meters, lancets, calibration solutions and batteries) in 2002 for diabetic patients not taking insulin enrolled in the Medicare B program was US $\$ 465,000,000$ ! The total cost of SMBG in those not taking insulin in the USA, which includes other patients aged $\geq 65$ years who were not enrolled in the Medicare B program, as well as all younger patients, is obviously much higher.

Many observational studies, some very large, have failed to show a benefit for SMBG in diabetic patients not taking insulin. One can postulate that an even larger one, or perhaps a better designed one, might finally give us a definitive answer. This seems unlikely for the reasons given above. Furthermore, to date, the randomised clinical trials available have either not shown a beneficial effect in these patients or had serious design flaws invalidating their conclusions. Thus, the dilemma of SMBG for diabetic patients not taking insulin; it is an expensive and popular procedure without an evidence base. We are left with the need to pursue the answer to this question with properly 
designed, randomised clinical trials. Given the available evidence, we are spending a tremendous amount of money on an unproven clinical methodology. Those resources might be better spent in other areas of diabetes care.

Acknowledgements M. B. Davidson was supported by NIH grant no. U54-RR014616.

\section{References}

1. Martin S, Schneider B, Heinemann L et al (2006) Self-monitoring of blood glucose in type 2 diabetes and long-term outcome: an epidemiological cohort study. Diabetologia 49:271-278

2. Davis WA, Bruce DG, Davis TME (2007) Does self-monitoring of blood glucose improve outcome in type 2 diabetes? The Fremantle Diabetes Study. Diabetologia DOI 10.1007/s00125006-0581-0

3. Francoiosi M, Pelligrine F, De Berardis GE; QuED Study Group et al (2001) The impact of blood glucose self-monitoring on metabolic control and quality of life in type 2 diabetic patients: an urgent need for better educational strategies. Diabetes Care 24:1870-1877

4. Karter AJ, Ackerson LM, Darbinian JA et al (2001) Selfmonitoring of blood glucose levels and glycemic control: the Northern California Kaiser Permanente Diabetes Registry. Am J Med 111:1-9

5. Pocock SJ, Elbourne DR (2000) Randomized trials or observational tribulations? N Engl J Med 342:1907-1909

6. Ziegler O, Kolopp M, Got I et al (1989) Reliability of selfmonitoring of blood glucose by CSII-treated patients with type 1 diabetes. Diabetes Care 12:184-188

7. Fontbonne A, Billault B, Acosta M et al (1989) Is glucose selfmonitoring beneficial in non-insulin-treated diabetic patients? Results of a randomized comparative trial. Diabete Metab $15: 255-260$

8. Nathan DM, McKitrick C, Larkin M et al (1996) Glycemic control in diabetes mellitus: have changes in therapy made a difference? Am J Med 100:157-163

9. Dorchy H, Roggemaans M-P, Willems D (1997) Glycated hemoglobin and related factors in diabetic children and adolescents under 18 years of age: a Belgian experience. Diabetes Care 20:2-6

10. Strowig SM, Raskin P (1998) Improved glycemic control in intensively treated type 1 diabetic patients using blood glucose meters with storage capability and computer-assisted analyses. Diabetes Care 21:1694-1698
11. Evans JMM, Newton RW, Ruta DA et al (1999) Frequency of blood glucose monitoring in relation to glycemic control: observational study with diabetes database. BMJ 219:83-86

12. Ohkubo Y, Kishikawa H, Araki E et al (1995) Intensive insulin therapy prevents the progression of diabetic microvascular complications in Japanese patients with non-insulin-dependent diabetes mellitus: a randomized prospective 6-year study. Diabetes Res Clin Pract 28:103-117

13. Davidson MB (2005) Self-monitoring of blood glucose in type 2 diabetic patients not receiving insulin: a waste of money. Diabetes Care 28:1531-1533

14. Welschen LMC, Bloemendal E, Nijpels G et al (2005) Selfmonitoring of blood glucose in patients with type 2 diabetes who are not using insulin: a systematic review. Diabetes Care 28:1510 1517

15. Sarol JN Jr, Nicodemus NA Jr, Tan KM et al (2005) Selfmonitoring of blood glucose as part of a multi-component therapy among non-insulin requiring type 2 diabetes patients: a metaanalysis (1966-2004). Curr Med Res Opin 21:173-184

16. Allen BT, DeLong ER, Fuessner JR (2002) Impact of glucose self-monitoring on non-insulin-treated patients with type II diabetes mellitus: randomized controlled trial comparing blood and urine testing. Diabetes Care 25:1928-1932

17. Estey AL, Tan MH, Mann K (1990) Follow-up intervention: its effect on compliance behavior to a diabetes regimen. Diabetes Educ 16:291-295

18. Muchmore DB, Springer J, Miller M (1994) Self-monitoring of blood glucose in overweight type 2 diabetic patients. Acta Diabetol 31:215-219

19. Davidson MB, Castellanos M, Kain D et al (2005) The effect of self monitoring of blood glucose concentrations on glycated hemoglobin levels in diabetic patients not taking insulin: a blinded, randomized trial. Am J Med 118:422-425

20. Schwedes U, Siebolds M, Mertes G; for the SMBG Study Group (2002) Meal-related structured self-monitoring of blood glucose: effect on diabetes control in non-insulin-treated type 2 diabetic patients. Diabetes Care 25:1928-1932

21. Jaber LA, Halapy H, Fernet $M$ et al (1996) Evaluation of a pharmaceutical care model on diabetes management. Ann Pharmacother 30:238-243

22. Kwon HS, Cho JH, Kim HS et al (2004) Establishment of blood glucose monitoring system using the Internet. Diabetes Care $27: 478-483$

23. Guerci B, Drouin P, Grange V et al (2003) Self-monitoring of blood glucose significantly improves metabolic control in patients with type 2 diabetes mellitus: the Auto-Surveillance Intervention Active (ASIA) study. Diabetes Metab 29:587-594 